DOI: 10.2478/ausfm-2014-0019

\title{
Sensations of Dysphoria in the Encounter of Failing Bodies: The Cases of Karaoke by Donigan Cumming, Last Days by Gus Van Sant, and Drunk by Gillian Wearing
}

\author{
Élène Tremblay \\ University of Montréal \\ E-mail: elene.tremblay@umontreal.ca
}

\begin{abstract}
The essay examines films and video installations that present the figures of suffering bodies and trigger strong dysphoric sensations through empathy: Karaoke (1998) by Donigan Cumming, Last Days (2005) by Gus Van Sant, and Drunk (2000) by Gillian Wearing. In addition to strong pathemic strategies that intensify the reception of the image, these artworks also contain counter-pathemic elements that distance the viewer from pathos. These long, moving, close examinations of pathemic physical states not only project the viewer into a frozen, insistent, and fascinated gaze at the suffering body and place him or her in a mirrored passive position but also offer an opportunity to move from sensation to sentiment, and then to sensitivity toward and experience of various stages of the empathetic response.
\end{abstract}

Keywords: Body, pathos, counter-pathos, empathy, dysphoria, video art, Donigan Cumming, Gus Van Sant, Gillian Wearing.

In this essay, I discuss films and video installations that present figures of the sick, dying, or intoxicated body and that trigger sensations associated with fear of death and physical decline. In the presence of these suffering figures, the viewer feels discomfort in his or her own body through an empathetic response. The viewer's strongly dysphoric bodily sensations come to signal his or her empathetic bond with others - a bond that he or she may accept or reject when it provokes dysphoric sensations. I argue here, as I did in my recent book L'insistance du regard sur le corps éprouvé. Pathos et contre-pathos (The Insistent Gaze upon the Afflicted Body: Pathos and counter-pathos, Tremblay 2013a), that these film and video works act as spaces for the viewer to negotiate and exercise empathy and the accompanying dysphoric sensations. 
In the artworks under examination here, the body appears pathemic, failing, troubled, suffering, and weak in its postures, movements, and appearance, allowing an empathetic contact with the viewer's body. Using the bonding power of the pathos conveyed by the suffering figure, along with long observations strategies, these artists practise an art of the encounter with the other represented, rather than an art of the narrative. They do so through an attempt at "reaching the bodies before the discourses," as Deleuze puts it in his book The Time-Image (Deleuze 1989, 172).

Artists and filmmakers who use the figure of the suffering body obviously want to provoke dysphoric sensations and empathetic responses, but many of them today are reluctant to use such pathos-loaded figures without questioning or disrupting their effect. Given that pathos is well known to trigger automatic responses and sensorial schemas, many artists, including Bertolt Brecht, have tried to use counter-strategies to free the viewer from these reflex-based bonds. But how does one keep the viewer from being overwhelmed without making the emotion-triggering device ineffective or risking a loss of empathy?

\section{Pathos and Counter-Pathos}

The rhetoric of pathos is a proven vector for inspiring fascination and sensation in the viewer. The posture of the engaged, emotional viewer indicates an intense, passionate relationship with the images in which the viewer is captivated, eyes riveted to the artwork. Through empathy, the viewer associates his or her own body with the bodies experiencing physical and emotional pain on screen.

The term "pathos" is used here in the sense of "the suffering happening to someone." Something that conveys pathos is pathemic, and something that disrupts and counteracts pathos is counter-pathemic. As Mériam Korichi defines it in her book Passions, "The Greek meaning of the term [pathos] refers primarily to the idea of 'suffering' or 'pain,' as revealed in the Homeric sense of pathein to endure a treatment or be punished - but the pain is not necessarily intended in the physical sense and the meaning is specific to the designation of mourning - penthein, the same root as pathein, meaning 'to be in mourning, to lament the death of someone' - so that pathema, 'what happens to someone, suffering, misery, disease' refers not only to the idea of a passive state, but also to the significance of this passivity, this suffering." (Korichi 2000, 238, our translation.)

Korichi establishes in this definition that the pain happening to someone takes on meaning in the eyes of a witness; it is experienced by an outside viewer. The 
figure of the mourner can be associated with the viewer who feels pain through another's pain, to which he or she is the passive witness. Pathos is revealed as a relational device between the sufferer and the viewer - as an emotion-carrying device, moving from one body to another.

Not only do the three artworks discussed here display suffering bodies but they also show movement both toward and away from the pathos conveyed by those figures. The former direction of movement creates a fusional empathetic response to the suffering figure, whereas the latter creates a distance that reduces the dysphoric sensation and can favour self-observation of empathetic somatic responses. Viewers can thus experience sensory fascination before being released from the overwhelming power of pathos. Counter-pathos is created by the distancing made possible by diverse strategies, such as activation of doubt, and the inclusion of signs of mise en scène, repetition, different versions or emotional treatments of the same scenes, comic relief, ruptures, and offering a very long and repeated observation time that can foster self-examination and reflection. This is particularly true in video art installations and a certain form of auteur cinema, in which reflexive practices take the viewer's role into consideration and make the viewer aware of that role.

Phoria and dysphoria - pleasure and displeasure - are disseminated primarily through bodily empathetic sensations before they become the object of conscious perception and analysis. The point of contact with the viewer highlighted by Wearing, Cumming, and Van Sant is, above all, the human body's ability to communicate through its postural and kinesthetic dimensions. Pathos is expressed through the non-verbal performance of the lead actor in Van Sant's Last Days, who, like Wearing's drunken figures in Drunk, loses control over his body in the repeated and extended motion of falling. Both Last Days and Drunk, because they communicate mainly through the body, bear similarities to contemporary dance practices, especially to choreographer Pina Bausch's dance-theatre (tanztheater).

Pathemic postures and movements make bodies appear empty, lacking intentionality, caught in fate, displaying motion failure. These bodies' characteristic postures are bent backs, bowed heads, hanging arms, curved chest, sitting or lying position, clumsiness, tilting of the head and body, slumping. Their movements are the fall, stumble, tumble, trip, and drop. They stagger, totter, surrender, and quit as if they have lost self-control, are disabled, or are too heavy or weak. Their functionality is disturbed, as limbs and organs do not perform as expected. Their sensori-motor schemas are disrupted. Their postures and movements come to signify disorder, weakness, contingency, vulnerability, 
loss of control, resignation, and the foreshadowing of a death to come, the sight of a still body bereft of life.

Through detailed examinations of pathemic body states offered by filmic strategies such as the long take and repetition, these artworks offer the viewer the opportunity to move from sensation to sentiment to sensitivity. Sensations happen in the viewer's body; sentiments, in the viewer's mind - that is, on a more reasoned stage; sensitivity refers to the broader social ability to bond with others.

\section{Karaoke}

Karaoke, ${ }^{1}$ by Donigan Cumming, a video loop presented as a larger-than-life projection in a gallery, uses pathemic and counter-pathemic strategies at two very distinct moments.

The camera first lingers in a very tight close-up - at an "intimate distance," as the anthropologist Edward T. Hall (1966) would put it, or a haptic distance - on the face of an old man whose physical appearance leads us to believe that he is in agony. His eyes appear opaque and blind, and he seems to breathe with difficulty through an open mouth as he passes an atrophied tongue over his parched lips and swallows painfully. In the background, we hear music, a simple and joyous song, the lyrics of which are incomprehensible. The camera begins a slow pan down the prostrate body, finally revealing the man's foot as it beats in time to this strange music. Then, the camera pans back up to the old man's face - and we understand that this is the same shot as the first, but reversed, as the music plays backwards. The work is divided into two parts: in the first part, we identify strongly and empathetically with the agony of the reclining body; in the second part, we revisit our initial judgment as we discover the old man's foot expressing his enjoyment of the music.

The use of the extreme close-up on the dying old man's body induces haptic perception. The intimate distance into which the viewer is projected allows him or her to capture the details of the skin - its wrinkles and folds - the dryness of the mouth, the veil that covers the eyes and indicates that vision is no longer possible. This intimate distance of the haptic perception of a dying body is unusual and brutal for the viewer, who is drawn in and cannot escape. As in an intimate relationship, personal boundaries come into contact and intertwine.

1 Karaoke is part of a video installation titled Moving Stills (1998), by internationally renowned Canadian artist Donigan Cumming. For three minutes the camera is focused on a dying old man lying on a bed, panning down and up his body. This three-minute video is projected in a loop with two other videos, each of which shows a character crying and displaying despair, also shot in close-up (Petit Jesus and Four Storeys). 
Marks $(2000,188)$ has explained, "The haptic is a form of visuality that muddies intersubjective boundaries." Such a perception, as induced by Cumming, is an imperative and invasive prescription to see and recognize the Other.

"Tactile epistemology involves thinking with our skin, or giving as much significance to the physical presence of an other as to the mental operations of symbolization. This is not a call to willful regression but to recognize the intelligence in the perceiving body. Haptic cinema, by appearing to us as an object with which we interact rather than an illusion into which we enter, calls upon this sort of embodied and mimetic intelligence. In the dynamic movement between optical and haptic ways of seeing, it is possible to compare different ways of knowing and interacting with an other.” (Marks 2000, 190.)

The forced encounter through haptic visuality makes the viewer's body react and engage in an empathetic relationship marked by dysphoria. These dysphoric feelings that invade the viewer's body make him or her feel the strength of his or her sympathy, as well as the ambiguity of the attraction-repulsion duality that characterizes it.

The viewer, at first overwhelmed by dysphoric emotion and expecting to share only pain and discomfort with the man in the video, is later relieved to discover that the man enjoys the music that is playing. Upon this realization and reversal, the viewer is partially relieved of the automatic response of his or her mirror neurons in front of the dying old man. That beating foot is a snub to death - and to the viewer's propensity to pity and reduce the other. The recumbent figure comes to life and indicates that life overcomes the immobility of death.

During the unfolding of Karaoke, dysphoria first enters the viewer's body through empathy with the dying body; then phoria arises through cognition, pushing the dysphoria aside. Dysphoric sensations are invasive, and the disruptive strategies employed by Cumming can help to counter their powerful effect.

\section{Last Days}

Useful to our discussion is Deleuze's observation that the sensori-motor schemas of characters' bodies in post-Second World War films are broken. The film character is no longer a hero with a purpose and a task in a grand narrative but a figure wandering in a world from which he is alienated, as the camera follows him. The character of Blake, inspired by the tragic figure of Kurt Cobain, in Gus Van Sant's Last Days is certainly an example of that wandering figure. Last Days bears an aura of pathos in its reference to the actual suicide of the well-known and beloved musician. 
Blake appears to be unaware of himself and barely says a word throughout the film. Obviously, communication here occurs not through words but through the body. It is through the body that we perceive Blake's mental state and his relationship or lack of relationship with places, objects, and others. Falls, collapses, and losses of consciousness punctuate his journey until his very last fall to his death at the end. Throughout the film, we are witnessing Blake's body break down - emptied of its power, its intentionality, and, ultimately, its consciousness. Not only do his actions not seem to have any purpose but his whole body indicates, through his postures, the decomposition of his motor schema. Since we are informed that Blake is a character inspired by Kurt Cobain, we can therefore already consider that he is a dead man - a walking dead man.

From the beginning, Blake appears small, fragile, and lost in a forest landscape through which he moves with difficulty. Dressed in simple, dirty red-and-white pyjamas, his presence in the forest seems anachronistic. When he finally arrives at a house and picks up a shovel, he slips and falls again before going to dig up a box that we guess contains the drugs that he has tried to stop using and which he will consume right after. We are witnessing Blake's slow slippage toward his own obliteration and his being overpowered by the death instinct.

The figure of the suffering body of Christ is frequently evoked; Blake appears particularly skinny: when he washes in the river, we can see his bones through his skin. When, intoxicated, he goes to his bedroom with a bowl of cereal, falls backward onto the bed, and then awkwardly raises his head and upper body, it looks as if a soul is leaving a dead body. This scene foreshadows the final scene of his death, when, through a superimposition effect, we see his ghostly body emerging from his dead body and rising. The reference to Christ is also openly made earlier in the film, when Van Sant brings in two Jehovah's Witnesses who explain the role of the sacrificial lamb - which is, according to them, to take the place of Jesus - and then shows us Blake walking on all fours like a lamb.

Later, when Asia opens a door against which he has fallen asleep, Blake falls again in a heap, making her fear that he is dead. The scene is repeated from two different points of view: inside and outside the room. Another repeated scene is the one of his arrival at the house from the forest; the first time, he is wearing a white T-shirt, whereas the second time, he is wearing a red-and-black striped sweater like the one that Kurt Cobain wore on the day of his death.

With these repetitions and variations, Van Sant borrows radical strategies from experimental film and video art to create a disrupted fictional time apart from action-image and the conventional linear narrative. These strategies break up the 
naturalism of linearism and suggest multiple points of view and interpretations. The temporality that Van Sant creates throughout Last Days is one of slow observation and pathemic time. As they follow Blake, viewers are left to linger in pathos and witness his slow physical decline. This process is expressed in the repeated and extended movement of the fall and by the body losing its power and drive. The exaggerated duration of Van Sant's takes on the failing body bears a pathemic effect and acts as his pathosformel. ${ }^{2}$

Some counter-pathemic elements can be observed in the absurd apparition of the Yellow Pages salesman and the Jehovah's Witness brothers, whose anachronistic presence makes us laugh. These characters also play the role of a normative background against which the difference of Blake's behaviour stands out.

\section{Drunk}

Similarly to Van Sant with Last Days, British artist Gillian Wearing slowly observes, in exaggerated duration, falling intoxicated bodies in her video installation Drunk. ${ }^{3}$ She asked real alcoholics living in the street to come in her studio to be filmed on a white background. The resulting films are exhibited in galleries in a monumental three-channel video projection that renders the subjects larger than life. They stagger, urinate, fight, and fall asleep on the floor. Here, the failing motor skills of the bodies are emphasized by isolating them against a white background. The viewer can identify, beyond the identity of the persons depicted, with body failure as a common, shared space experienced by everyone to different degrees.

But the identity of the alcoholics, their clumsy bodies, can also provoke counterpathemic laughter and reduction to caricature. The responsibility for the empathic link is thus returned to the viewer. If the viewer identifies with the people on screen, the pathos in this work is effective. Only the extended duration, the loop presentation, the bodies magnified by monumental projection, the displacement of the drunks into a studio, and the effect of the space of art mediation can offer a slight distance: the drunks' movements appear choreographed and almost graceful as they exhibit disturbed bodies whose restraint and self-control have deserted them.

2 Pathosformel is a German word used by art historian Aby Warburg to describe the formulas of pathos in artworks. See discussion later in this text.

3 Gillian Wearing, Drunk, three-channel video projection, black and white, with sound, 23 minutes, 1999. In a larger-than-life projection, real drunk people stagger and fall in a white studio. Wearing is a conceptual artist from Great Britain who won the Turner Prize in 1997. 


\section{Pathemic Time}

In these three works pathemic bodies are caught up in pathemic time - a doubling or tautological strategy that subjects both the viewer and the represented figure to the long duration of dysphoric experiences. The frozen repetitive time of this pathemic strategy afflicts the passive viewer through the use of the long take in all of the works, the repetition of the loop in the video installations, and the variations on the same scene repeated in Last Days.

Pathemic time does not unfold and cannot sustain the development of a tragic, heroic narrative but can only express a passive enduring of time. The duration offered to pathos by the long take and the video loop acts in the same way as the imposition of the pathemic posture on the human figure: it slows things down to an almost stationary state, it stretches and repeats. Pathemic time bears insistence. It insists and stares at the filmed figure and projects the viewer into a staring, attentive position (Tremblay, 2013a).

In Karaoke, the recumbent figure of the emaciated, dying body evokes the corpse to come as well as the image of the dead Christ lying wrapped in his shroud. This image provokes fear of impotence and weakness and of one's own death. According to art historian Aby Warburg, pathos, by the strength of the emotions it stirs, has configured and modelled representations throughout history. Emotions imprint matter, set it in motion, in the emblematic sculpture of the Laocoön. Warburg names this phenomenon pathosformel, or pathos formula, an energy based on passion, fear, and fascination that emerges not only in iconographic themes but in a work's formal and aesthetic qualities - for example, in the movement of the twists and folds of the clothes and draped fabric and in the tormented bodies of the Laocoön (Tremblay 2013a).

In the video and film works of Cumming, Wearing, and Van Sant, the passion or fear derived from pathos does not imprint its movement on matter as it did in the statues of antiquity, but is translated into the frozen, fascinated gaze at - the slow and repeated observation of - emaciated, failing bodies. A fascination with pathos ties the viewer's gaze to this image, as do the repetition of the looped presentation and the long take, all of which enclose the subject in an endless temporality that could be associated with purgatory. Repetition and the emphasis of the insistent gaze embodied by the camera and the editing become figures of the fascinated gaze. This slow, repetitive observation is the sign of a temporality affected by pathos. One could say that in these time-based artworks, Warburg's pathosformel gives shape to time rather than matter. This shape - or "energy," as Warburg would put it 
- carries the fear of death and decay. Although, unlike the characters in Warburg's corpus of study and the ancient portrayals, the characters depicted here are not tragic heroes but resolutely modern anti-heroes whose fate and misfortune provoke fascination. The meaning of their fate is not provided by a narrative but remains rather opaque in the long, slow observation time of this insistent gaze.

The empathetic response engages the viewer's entire body in a relational dynamic. Empathy here is kinesthesic (through movement) and thymic (through pain). Kinesthesic and thymic empathy trigger activity in the areas of the viewer's brain linked to the gestures, movements, and pain that he or she witnesses. If a figure is slowly falling, the part of the viewer's brain linked to that movement reacts, just as one might yawn if one watches a person who is yawning. As neuroscientist Tania Singer and her colleagues have observed, ${ }^{4}$ empathetic reactions are produced in the area of the brain concerned with that action but do not use all of the area, as does the brain of the person actually performing the action. Even if empathy unfolds, what is felt is not the same as what is observed. Moreover, the viewer can modify (reduce) his or her reaction with awareness. ${ }^{5}$ When experiencing fiction, the viewer perceives emotions as true and subscribes to them through empathy, but he or she can also remain aware that it is a work of fiction and therefore maintain distance and the possibility of controlling his or her emotions.

Because the viewer agrees to follow the rules of fiction and to momentarily believe the reality of his or her emotions, empathy can occur. Fiction offers an empathetic exercise based on the suspension of disbelief. Faced with documentary images of people in difficulty presented in the gallery, however, one cannot avail oneself of the mediation of the actor. Perceiving the truth of the people represented on screen, the viewer is instead placed in the uneasy position of the voyeur. Gazing at such documentary figures in video installations, he or she can choose either to escape or to take on the voyeuristic role and immerse himself or herself in its accompanying fascination and dysphoria. In either case - entering

4 "Our data suggest that empathizing with the pain of others does not involve the activation of the whole pain matrix, but is based on activation of those second-order re-representations containing the subjective affective dimension of pain." (Singer and al. 2004, 1161.)

5 "Consistent evidence shows that sharing the emotions of others is associated with activation in neural structures that are also active during the first-hand experience of that emotion. Part of the neural activation shared between self- and other-related experiences seems to be rather automatically activated. However, recent studies also show that empathy is a highly flexible phenomenon, and that vicarious responses are malleable with respect to a number of factors - such as contextual appraisal, the interpersonal relationship between empathizer and other, or the perspective adopted during observation of the other." (Singer and Lamm 2009, 81-96, 81.) 
the movie theatre or the gallery - the audience knows that dysphoric emotions may be part of the viewing experience. Art and fiction generate emotions, without calling upon the urgent and immediate obligation to act or the threat of real situations. Both prepare people, to a certain degree, to experience pain to themselves and others. In this expansion of viewers' emotional experience, the figure of the suffering body plays the role of a key immediately opening the doors of empathy. Distancing strategies close these doors slightly to render reception more bearable and reasonable. This possibility of reasonableness in the empathic response offered by the artwork promotes ethical deliberation regarding the viewer's reactions vis-à-vis the pain of others.

As the viewer watches a film or video installation, the experience of relative pain by empathy also creates displeasure reactions in his or her brain. In these three artworks, one can observe three different kinds of pain; first, the pain of the figure represented on screen; second, the viewer's own empathetic pain, similar to but different from the one experienced first hand by the figure represented; third, the viewer's pain of experiencing displeasure by empathy (secondary displeasure). This secondary displeasure is added to the dissimilar pain experienced in empathy, as Jacques Fontanille (2007, 39, our translation) points out: "It is a question not of directly sharing the pain or pleasure of others but of managing the indirect products of its exhibition to us, which I shall call secondary pleasure and displeasure."

Empathy appears to be based not on altruism but on the desire to relieve oneself of dysphoria. Reactions as diverse as looking away, fleeing, staring, and reducing and diminishing what is perceived are manifestations of the same process of experiencing and trying to relieve oneself of the dysphoric sensations felt through empathy. Both the artist filming and the viewer watching experience these reactions. In the filmmaker's case, they translate into enunciation and aesthetic strategies.

The slight distance of counter-pathos offered by Karaoke, and in a lesser way by Last Days and Drunk, allows the artists and their audience to create a space in which it becomes possible to "manage" secondary dysphoria. In the long duration of pathemic time, the viewer becomes attentive to his or her own empathetic responses. The distance offered by the experience of a pathemic time doubling a pathemic representation along with a movement against pathos, allows us "to feel ourselves feeling," as Vivian Sobchack $(2004,77)$ puts it, and to observe the progress and changes in sensations and emotions from a fusional disturbing state to a relatively more distanced, reasoned position. In these artworks, sensations 
and emotions not only are part of the cognitive experience but become their very subject and object of examination. In the case of the video loop in the gallery space, because viewers are free to stay in front of the projection or leave, they can modulate the duration of their exposure to pathos. On another level, they can try to modulate their internal reactions to the pathos by creating "emotional armour" for themselves.

Unlike in Brechtian strategies, pathos here is not countered at the very beginning, at the root, which would render the figures non-credible and the pathos ineffective; only later on, after allowing pathos to unfold and touch the viewer, do these artworks bring him or her to observe and reconsider what has happened. Being touched and then distanced allows for cognition with emotion and contact, away from simple cynicism and indifferent distance. The awareness of the action of pathos and empathy in the viewer's perception is made possible first by bringing forward the body figure and its powerful affects and then through repetition, variations, a slow and long observation process, and ruptures of pathos with humorous elements. Through this process, these works propose an encounter in which the viewer's empathy is revealed, tested, and becomes part of a process of self-examination.

This experience of dysphoria and phoria, felt successively, in the double movement toward and away from pathos observed in Karaoke reveals ambivalence. This ambivalent position, which both binds us to and frees us from the suffering of others represented, forms a new space for deliberation and the negotiation of pathos along the axis of the empathetic bond. The figure of the suffering body plays the role of an agora, a common space, in which encounter, self-awareness, and empathy can be tested in simulation and sensations experienced through empathy, with their bonding role, and become the object of embodied sensitive observation and ethical deliberation. 


\section{References}

Deleuze, Gilles. 1989. Cinema 2: The Time-Image. Minneapolis: University of Minnesota Press.

Didi-Huberman, Georges. 2002. L'image survivante: histoire de l'art et temps des fantômes selon Aby Warburg [The Surviving Picture: History of Art and Time of Phantoms at Aby Warburg]. Paris: Les éditions de Minuit.

Fontanille, Jacques. 2007. Le temps de la compassion. La diffusion thymique et ses régimes temporels [The Time of Compassion. The Thymic Diffusion and its Temporal Regimes]. Le plaisir des sens. Euphories et dysphories [The Pleasure of the Senses. Euphorias and Dysphorias], ed. Louis Hébert, 23-51. Quebec City: Les presses de l'Université Laval.

Hall, E. T. 1966. The Hidden Dimension. Garden City, NY: Doubleday.

Korichi, Meriam. 2000. Les passions. [The Passions] Paris: Flammarion.

Marks, Laura. U. 2000. The Skin of the Film: Intercultural Cinema, Embodiment, and the Senses. Durham and London: Duke University Press.

Sobchack, Vivian. 2004. Carnal Thoughts: Embodiment and Moving Image Culture. Berkeley and Los Angeles: University of California Press.

Singer, T. and C. Lamm. 2009. The Social Neuroscience of Empathy. In The Year in Cognitive Neuroscience, ed. Michael B. Miller and Alan Kingstone, vol. 1156: 81-96.

Singer, T. and al. 2004. Empathy for Pain Involves the Affective but not Sensory Components of Pain, Science, 303 (5661): 1157-1162.

Tremblay, Élène. 2013a. L'insistance du regard sur le corps éprouvé. Pathos et contre-pathos [The Insistent Gaze upon the Afflicted Body: Pathos and counterpathos]. Udine: Forum.

Tremblay, Élène. 2013b. Le phénomène de l'empathie dans l'espace figural du corps éprouvé [The Phenomenon of Empathy in the Figural Space of the Afflicted Body]. In Corps et espaces [Bodies and Spaces], ed. Sabine Kraenker and Xavier Martin. Helsinki: Les publications romanes de l'université d'Helsinki. 


\section{List of Figures}

Figure 1. Screenshot from video Karaoke, by Donigan Cumming (1998). Courtesy of the artist. Figure 2. Screenshot from Last Days by Gus Van Sant, 2005.
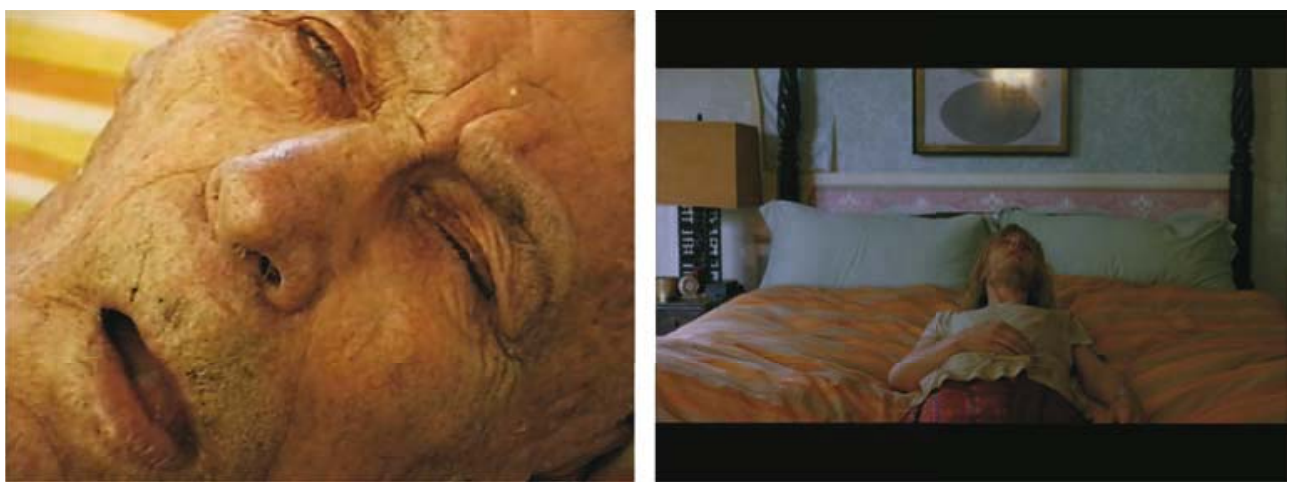

Figures 3-4. Screenshots from Last Days by Gus Van Sant, 2005.
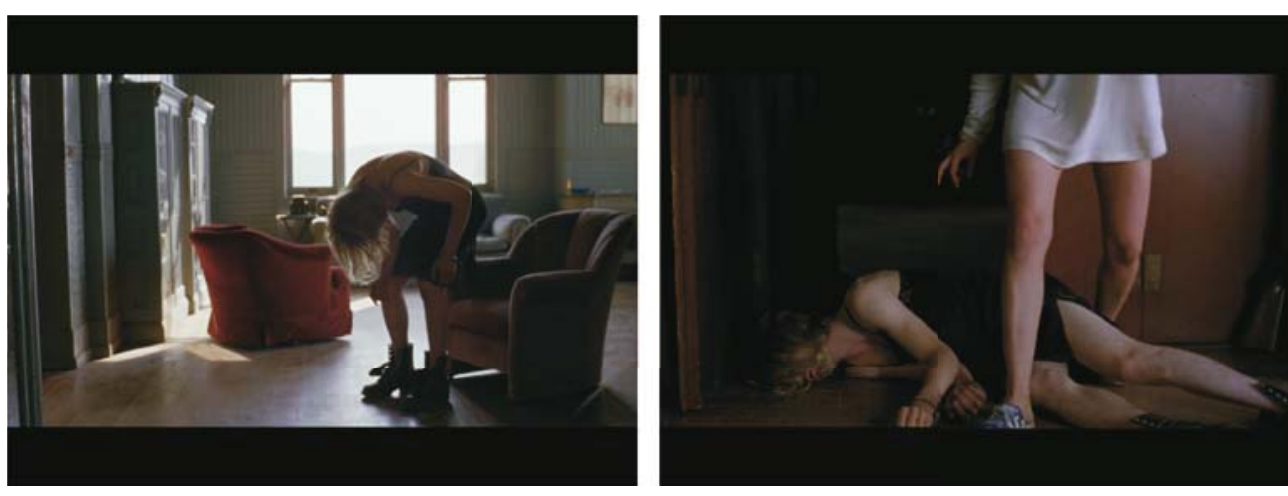